\title{
Unmet Fertility Expectations and the Perception of Fertility Problems in a Malawian Village
}

\author{
Janine Barden-0 'Fallon ${ }^{1}$
}

\begin{abstract}
ABST RACT
This study analyses in-depth interviews with 15 women and 11 men living in a rural Malawian village to know how fertility problems are identified and interpreted in a context of high fertility demand. Results of the analysis show that although ideal family size may be falling, expectations to quickly achieve pregnancies remain high. Individual and social expectations about childbearing inform the perception of fertility problems if more than a few months pass without a noticeable pregnancy. Such problems are usually attributed to women, especially if the male partner has proven his fertility with another spouse/ sexual partner. Community education on variation in the time to conception is needed, as is an understanding of how perceived infertility, regardless of actual waiting timeto pregnancy, can lead to treatment seeking and risky sexual behaviour. (A fr J R eprod H ealth 2005; 9[2]: 14-25)
\end{abstract}

\section{RÉSUMÉ}

Cette étude fait une analyse des interviews en profondeur qui ont été recueillies auprès de 15 femmes et 11 hommes qui habitent dans un village rural malawien. E lle a comme but d'examiner comment les problèmes de la féconditésont identifiés et interprêtés dans un contexte de la damande pour la haute fécondité. Les résultats de l'analyse montrent que bien que la taille familiale idéale baisse, les espérances de devenir rapidement enceinte demeurent considérables. Les attentes idividuelles et sociales concernant la procréation justifient la perception des problèmes de la féconditési, à la fin de quelques mois, il n'y a pas de grossesse perçue. On a souvent l'habitude d'attribuer de tels problèmes à la femme, surtout si le partenaire mâle avait déjà fait preuve de sa fécondité auprès d'une autre partenaire sexuelle. II faut éduquer la communauté sur la variation par rapport du temps de la conception, de la même manière qu'une compréhension de la façon dont la stérilité perçue, sans compter sur la vraie période d'attendre la grossesse, peut aboutir à la recherche du traitement et au comportement sexuel à risque.(R ev A fr SantéR eprod 2005; 9[2]: 14-25)

KEY WORDS: Infertility, ex pectations, interpretation, women

${ }^{1} \mathrm{C}$ arolina Population $\mathrm{C}$ enter, $\mathrm{U}$ niversity of $\mathrm{N}$ orth $\mathrm{C}$ arolina at $\mathrm{C}$ hape $\mathrm{H}$ ill

Correspondence: D r JanineB arden-0 'F allon, M easure/ E valuation, 206 W . Frank lin St., C B \# 8120, C arolina Population Center, U niversity of N orth C arolina at C hape H ill, Chape H ill, N orth C arolina 27516-8120 or by phone (919) 843-3132 or email to bardenof@ email.unc.edu. 


\section{Introduction}

Infertility is known to have a substantial negative impact on the lives of women and men throughout sub-Saharan A frica. The psychosocial consequences of fertility problems are extensive, and they range from ridicule, disrespect, social exclusion and discrimination to feelings of depression, worry, anger and grief. ${ }^{1-3}$ Infertile women are also likely to experience partner neglect or abuse, marital instability, and poverty; as in some areas infertile women are not permitted to own or inherit land. ${ }^{3-6}$ I nfertile individuals in sub-Saharan A frica have also been found to have multiple sexual partners and to be at high risk of contracting HIV and other sexually transmitted infections (STIS)..$^{7-9} M$ any of these negative consequences can also be experienced by individuals who have given birth to one or more children but are unable to become pregnant again. ${ }^{6,10}$

The consequences of infertility are not exclusively borne by the affected individuals; they also spread to the larger society. For example, infertility can interfere with the normal social functions of a community. Practices related to kinship, lineage, inheritance, religion and household residence patterns, among others, are impacted by infertility, and they help to explain why infertility is seen as a group concern among many sub-Saharan populations. ${ }^{11,12}$ The high personal and social costs of infertility imply that infertility should be of major public health concern, although its treatment and prevention has traditionally not been considered a programmatic priority for resource-poor countries. ${ }^{13}$

Published research has provided much insight into the individual and social consequences of infertility, while elucidating local beliefs about the causes of problematic fertility and the types of treatment sought. ${ }^{13} \mathrm{H}$ owever, there are few studies that closely examine how individuals perceive and interpret their reproductive status. 0 ne noteworthy exception is an examination of how the Sara, Chad's largest ethnic group, make sense of their reproductive experiences. ${ }^{14}$ Such research provides the basis for a better understanding of local constructions of infertility; how, when and why individuals perceive fertility problems and how they respond to their perceptions. This type of knowledge is useful in informing efforts aimed at preventing infertility and the risky sexual behaviours that are often associated with it. It is also useful in informing efforts aimed at reducing the demand for unnecessary infertility treatments.

The objective of the present research was to investigate how individuals identify fertility problems in an area of high fertility demand. The specific aim was to examine how fertility expectations are related to perceptions of fertility difficulties among women and men in a rural Malawian village. To achieve this, in-depth interviews were conducted to explore the personal and social definitions of normative fertility and fertility difficulties among this population, and to relate fertility demand to perceptions of fertility problems.

The expressions "fertility difficulty" and "fertility problem" are general terms used to refer to the entire range of fertility impairment represented in this study, including primary infertility (childlessness), secondary infertility (the inability to become pregnant after the birth of at least one child), sub-fertility (low fertility), subfecundity (long waiting times to pregnancy), or other difficulties in getting pregnant when desired. The term "fertility expectations" is directly related to the concept of fertility demand, and is based on economic models of fertility behaviour. ${ }^{15,16}$ In these models, fertility demand is a hypothetical measure of how many children an individual or couple would want if there were no constraints to childbearing, and is often used interchangeably with "fertility preference", "fertility desire" and "ideal family size". "Fertility expectations" is used in this study interchangeably with fertility demand, and is intended to take a comprehensive view of reproductive expectations, including the timing 
and spacing of births and the relative ease of becoming pregnant. Fertility demand, both at the individual and societal levels, can influence reproductive behaviours such as through the use or non-use of family planning as well as through personal attitudes and social norms about childbearing, fertility and infertility. Fertility demand is considered to be high when the costs of fertility regulation outweigh the costs of childbearing (costs are understood to be real and potential, subjective and objective).

$M$ any populations of sub-Saharan A frica are in settings of high fertility and high fertility demand. In such settings, there is little or no voluntary childlessness and, as discussed earlier, there are often severe consequences for not achieving normativefertility. Whereas the influence of fertility demand on fertility trends and behaviours has been studied extensively, ${ }^{17-19}$ its association with perceptions of fertility status has not been examined to date. In particular, little is known about how individual perceptions of fertility status are influenced by individual and social fertility expectations. What happens when fertility experiences do not match expectations? How are fertility problems recognised and interpreted? This study attempts to answer these questions and add to what we know about how fertility status is interpreted in a sub-Saharan A frican context.

\section{Study Setting}

Malawi is a small sub-Saharan A frican country with infertility rates estimated to be in the uppermiddle range, as compared to other countries in the region. ${ }^{20}$ This study was conducted in M osiya, a village in the rural district of $M$ angochi, southeastern Malawi, around the tip of Lake Malawi. The district has slightly more than 610,000 people, mostly engaged in subsistence fishing and farming. ${ }^{21}$ The main ethnic group is the Yao, while the main religions in the district are Islam and Christianity. Polygyny is practiced; approximately
$21 \%$ of women are in a polygamous union. ${ }^{22}$ The total fertility rate for $M$ angochi $D$ istrict is the highest in the country (7.4 births per woman). ${ }^{23}$ Fertility demand is also high in the district: over half of all respondents in a recent populationbased survey reported wanting four or more children, and over $72 \%$ of females aged 15-35 years reported wanting a/ another child. ${ }^{22}$ Results from this same study also indicate that there is a high rate of perceived fertility problems among young women and men. Almost $20 \%$ of both women (aged 15-35 years) and men (aged 2045 years) reported that they (or their partner) had difficulty in getting pregnant, while ap proximately $7 \%$ of women and $5 \%$ of men suspected that either they or their spouses were infertile. ${ }^{24}$

$M$ angochi town is the administrative and economic centre of $M$ angochi $D$ istrict. $M$ angochi town has a population of about 25,000 and it lies along the Shire River, between Lake M alawi and Lake M alombe. It is about $320 \mathrm{~km}$ from the country's capital city of Lilongwe. The town has a daily market, a few restaurants and rest houses. It is the last stop for many travellers who are on their way to the lake resorts around Lake M alawi. The district hospital is located in the town as well as a family planning clinic, both of which represent a main source of reproductive health education and service provision for residents of the town and nearby villages. Mosiya is one of those villages. It is located across the river and within walking distance from the town. Travel between the Mosiya and Mangochi is very common and relatively easy due to a paved highway that runs through the town (directly in front of the hospital) and nearby villages.

\section{Study Design}

Twenty six interviews were conducted with 15 women and 11 men living in Mosiya village in June 2003. The interviews were conducted in private, at or near the respondents' homes. The local language was used. Respondents had a wide 
range of infertility experiences including primary infertility, secondary infertility, past fertility problems that have since been resolved, and no fertility problems whatsoever. Selection criteria included age between 20 and 60 years, women who had either had a live birth or attempted to get pregnant, and men who had either fathered a child or attempted to impregnate a woman. As with most qualitative research, the sampling was not intended to provide a representative sample of the general population.

The village chief was first approached to obtain his consent for the study to take place in the village. Hewas also consulted to help identify potential study participants by approaching community members who had fertility problems. $\mathrm{He}$ in turn sought the consent of such people to participate in the study. The interviewers then followed up with each potential participant to explain the purpose of the research project to them and obtain to their verbal consent before conducting the interviews. This method proved to be very successful for recruiting women, but only two men with fertility difficulties were identified by the chief. The male interviewer recruited the other male participants by randomly approaching households. This method provided a sufficient number of interviewees, although the interviewers had continual difficulty in finding men who were willing to discuss their infertility experiences. Some of the men ran away or went to hide when they were informed about the visit of the interviewers.

The interviewer guide included questions on the definition of fertility difficulties, fertility experiences and preferences, past and present perceptions of fertility status, and the fertility experiences of family members, friends and other community members. The guide was pilot tested in $M$ angochi town. I nterviewers made notes during each interview, including the circumstances and their impressions of the interview, and wrote a brief synopsis of the main issues that emerged. After data collection, the data were assembled and a description of the study participants including their birth histories was compiled. Transcripts were coded throughout the analysis to generate conceptual categories that condensed and related the ideas that emerged from the interviews. These conceptual categories were continuously compared to the raw data to ensure that the main concepts were well defined and reflective of the data.

The study was approved by the Institutional Review Board of the U niversity of N orth Carolina at Chapel $\mathrm{H}$ ill School of Public Health. Locally, it was implemented as an extension of the Malawi Pregnancy and STI Risk Perception and Avoidance Study, approved by the $\mathrm{N}$ ational $\mathrm{H}$ ealth Sciences Research Committee in A pril 2000 and August 2001.

\section{Shaping Fertility Expectations}

In practical terms, fertility expectations are what individuals expect to happen when they start trying to have children. Expectations can be influenced by a number of individuals and social factors. These include the social value given to children, the role of parenthood, family size preferences, observations and impressions of others' fertility experiences, and perceived norms regarding how long it should take to become pregnant. E ach of these issues was discussed in the interviews and the results are elaborated.

\section{Results}

TheSocial V alue of Parenthood and Family Size Preferences

In this setting, as well as in many others in subSaharan A frica, having at least one child is integral to identity formation and the definition of roles within the community. Parenthood provides an individual with an identity that has both social value and respect. H aving children is one way individuals become known in the community, because it brings titles of mother/ father and, 
someday, mother/ father-in-law and grandmother I father in a setting where these roles are much esteemed. Without the transition to parenthood often associated with becoming an adult, an individual has limited means of earning such respect. This is one reason villagers feel that infertile individuals are "belittled" and "made to feel like a fool". As one childless woman explained:

W hen you have a child you are respected and you are also recognised by people. But if you do not have a child you appear to be a fool in the presence of people, as if you are walking naked.

Theability to "prove" one's fertility is also important; men with the reputation of quickly impregnating women can boast of their ability to make anyone pregnant, and may even be sought after to help a woman with fertility problems.

When asked about the number of children desired, most respondents identified between three and five children, irrespective of whether they had experienced fertility problems or not. This appears to bea result of recent changes from wanting a traditionally large family. Respondents phrased their ideal family size in terms of wanting "only" four or five children or by saying, for example, "even five children is enough."

The way things are these days I don't think there is someone who wants to do that (have many children) (laughing), everyone wants to have a few children, like three, four or five, since things are expensive. (Male respondent)

If you have many children you fail to feed them and take care of them. (Female respondent)

Indeed, the number of children desired appeared to be a balance between being able to properly care for children and having enough children to provide support for the parents during sickness and old age. The practical and social benefits of children were greatly emphasized by a male respondent:

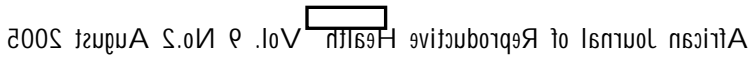

0 ur riches here lie in the hands of children.

$H$ aving one or two children is therefore not seen as sufficient, since some children may die or leave the village and not be able to perform necessary tasks such as fetching water or running errands. Furthermore, children from relatives that are taken in (especially by couples with no children of their own) are no substitute for one's own children.

A ccording to our culture, everyone is supposed to stay with his own children, you should not be counting on your uncle's or sister's children; when they grow older they do not attend to you and when you try to send them to do something, they say to you 'why did you not have your own children?' So, that is why people from this village try as much as possible to have five children so that during that time you should not have problems. (Male respondent)

0 bservations and Interpretations of 0 thers' F ertility $\mathrm{E} x$ periences

0 ne's fertility expectations are shaped by a lifetime of observations, interpretations and comparisons made of the fertility experiences of family members, friends and other community members. This section addresses how the experiences of other family and community members and interactions with family and community members help form impressions of childbearing and how long it should take to become pregnant.

To investigate how fertility expectations were informed by early exposures to fertility problems, respondents were asked to think back to their youth and talk about what they observed from other people's experiences with fertility problems and what they thought at that time of their own fertility prospects. As youths, community members may have noticed couples with no children or with only one child but did not spend much time thinking about it. Those who did so suspected that they may have misinterpreted what they saw, thinking at the time that the couples did not want children, that their "time for having 
children had not yet come", or that the couples "did not know how to make a baby". Of all the respondents, only two males remembered thinking that a physical problem could be the cause of childlessness. In addition, about one-fourth of respondents said they never noticed anyone with one child or no children when they were young. In contrast to these early observations, now as adults, all the respondents knew of others experiencing fertility problems and all but three could identify at least one family member who suffered temporary or permanent fertility problem.

$M$ any respondents did not think of their own fertility prospects as youth. When they had thought about it, they were sure that they would not have any problems getting pregnant and that having children would be very easy. The few who wondered about their prospect of being able to have children did so because they had a physical condition, such as abdominal pain, which caused them to be concerned. H owever, without having been exposed to infertility-related issues, the high fertility levels of the Mangochi D istrict suggest that the majority of youth saw families with many children as models of their own future childbearing. A misunderstanding of the fertility problems in the minority of couples with few or no children also contributed to the feeling that childbearing would be easy and was not an issue of personal concern. These early impressions of getting pregnant and bearing children continued into adulthood, often until these individuals started to try and have their own children.

\section{A cceptableW aiting T ime until P regnancy}

The time it "should" take to become pregnant emerged as a useful indicator of fertility expectations, as most individuals gave the same pattern of responses, stating in effect that it should take "two or three months, while for others it may take up to a year or longer." Two to three months was commonly mentioned because of the influence of family and community members on fertility expectations and of the pressures that may be exerted if the waiting time until pregnancy goes beyond a socially acceptable limit.

If a man marries this month, we start counting the months, one, two, thre; still if nothing happens the elders tell you to go for traditional medicines with your wife so that we should see. W hen you go there, you are given the medicines. Then you start taking them, and then within two to four months you find that the woman is pregnant.

Interviewer: So, does it mean that if four months elapse without being pregnant it is regarded as a problem?

Male respondent: $Y$ es, parents think so.

A fter two or three months of marriage they were greeting me like this: 'H ow are you?' 'I am fine.' 'H ow is our in-law?' 'She is fine' 'H ow about children, how are they?' I answer them that they are fine (laughing) while they know that they are mocking me. (Male respondent)

A nother male respondent described relationships with community members for a man with perceived fertility problems:

It pains him because people talk about him, they say things like 'three months have gone without impregnating your wife, look at your friends, they are only taking a week for their wives to become pregnant, but you are taking a longer time'. So things/ words like these bring pain to you, as if you are not a real man.

Such expressions indicate that the community helps to shape fertility expectations by creating a context in which pregnancy is expected to occur quickly. Pressure to reproduce within a specific length of time seems to be less intense after the first birth, as couples can practice postpartum abstinence and other forms of family planning to space births. H owever, it is still expected that once a pregnancy is again desired, it will require only a few months of waiting. 
On the surface, the responses to the question about how long it should take to become pregnant appear to acknowledge that it can take a year or longer. More likely, though, is that the "others" referred to are the ones considered to havefertility problems. Thus, rather than acknowledge that there are varying lengths of waiting times until pregnancy, it is usually a recognition that there are individuals with fertility problems who may take more time to achieve a pregnancy. The recognition of fertility problems was exemplified in the previous comment, in which elders recommended that help be sought from a traditional healer after three months of trying to become pregnant. Even more explicit examples came from respondents:

If everything is ok ay with you, you can only take two months, or the third month you may be pregnant. 0 thers tak e the whole year before being pregnant then after another two months they may be pregnant. ( $M$ ale respondent)

It shouldn't tak elong, maybe two to three months if they are both ok ay. (Female respondent)

\section{Perceiving F ertility $D$ ifficulties}

A number of different fertility experiences were represented in theseinterviews. The current number of living children of each of the respondents varied from none to eight, though only about one-third of them had three or more children. Table 1 shows the number of living children of each respondent by reported fertility difficulty. The table shows that women identified as having a difficulty in getting pregnant were more likely to be childless or have only one child as compared to the men, who in contrast were more likely to report experiences of temporary infertility and have more numbers of children. These experiences are a valuable reminder that fecundity problems can lead to infertility and sub-fertility (as experienced by many of these women). It can, however, be resolved and remain just that - perceived difficulties getting pregnant that do not translate into lower fertility.

Interview respondents were asked about their personal interpretation of "difficulty getting pregnant" in order to have a better understanding of how fertility problems are conceptualised in the community. Few respondents were able to answer direct questions about a personal interpretation of the phrase, providing, instead, causal definitions as to why an individual or couple has difficulties in getting pregnant. Of the few respondents providing actual definitions, one mentioned the need to seek medical assistance as a way to define a difficulty while the rest felt that the unsuccessful effort, or "failure" to become pregnant, is a clear indication of a difficulty in getting pregnant. 0 ne woman stated:

Table 1 Respondents' N umber of Living Children

\begin{tabular}{lcccc}
\hline $\begin{array}{l}\text { N umber of } \\
\text { children }\end{array}$ & $\begin{array}{r}\text { Women with } \\
\text { difficulty } \\
(\mathrm{n}=11)\end{array}$ & $\begin{array}{r}\text { Women without } \\
\text { difficulty } \\
(\mathrm{n}=4)\end{array}$ & $\begin{array}{r}\text { Men with } \\
\text { difficulty } \\
(\mathrm{n}=7)\end{array}$ & $\begin{array}{r}\text { Men without } \\
\text { difficulty } \\
(\mathrm{n}=4)\end{array}$ \\
\hline 0 & 4 & 0 & 1 & 0 \\
1 & 6 & 1 & 3 & 2 \\
2 & 0 & 0 & 1 & 1 \\
3 or more & 1 & 3 & 2 & 1 \\
\hline
\end{tabular}

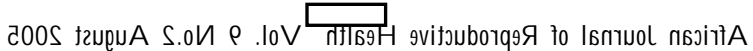


It means that despite all attempts to become pregnant nothing happens. Sometimes when you are sleeping with your husband you surely feel that that day you have conceived, but, mmmmh, all in vain. Y ou only do hard work without pay.

F urther insight on this issue was gained through an examination of the reasons each respondent felt $s /$ he had had a difficulty in getting pregnant. It thus became clear that the recognition of a fertility difficulty is based almost entirely on a waiting time to pregnancy that is individually and socially perceived as non-normative, and which can happen at any point in the reproductive lifespan. M iscarriages and child deaths are relatively common in this population. H owever, having experienced either of these events was not found to be influential in the perception of a difficulty, since women expressed feeling that they had proven their ability to get pregnant and were confident about their potential for future pregnancies and live births.

Based on individual assessments of the length of waiting time until pregnancy, a number of patterns emerged. Table 2 shows the identified patterns of waiting times to pregnancy by the reported fertility status of the respondents. The table shows that none of the individuals with fertility problems reported usual waiting times to pregnancy of six months or less. Most of the men who reported difficulties had long first birth intervals, followed by shorter normative birth intervals, whereas women who reported difficulties were represented in a number of categories. $M$ atching waiting time to pregnancy and parity revealed that despite the number of living children, any experience of a perceived long waiting time until pregnancy is interpreted as an experience of a difficulty in getting pregnant. This can happen near the beginning, the end, or at any time during the childbearing years.

The general theme that emerged from the analysis of fertility expectations and experiences is that a problem is identified when people's expectations do not match their experiences, particularly if the waiting time until pregnancy is longer than a few months. D espite the assortment of fertility experiences represented in the data, all of them fit the pattern of perceiving a difficulty when fertility expectations have not corresponded to actual experiences. However, sometimes fertility problems aren't easily apparent by looking at completed fertility or length of waiting time until pregnancy. For example, a woman in her mid-twenties with one child of about five years old explained how her fertility expectations had not been met. She described her experience as a younger woman, observing that others around her were already having children. She was so envious that she went to see a traditional healer even before trying to have a child on her own. She took medicines, began sexual relationships with her boyfriend (later spouse) and became pregnant right away. She tried

\section{Table 2 Pattern of Respondents' Length of Waiting Time until Pregnancy}

\begin{tabular}{lrrrr}
\hline $\begin{array}{l}\text { Length of birth } \\
\text { interval }\end{array}$ & $\begin{array}{r}\text { Women with } \\
\text { difficulty } \\
(\mathrm{n}=11)\end{array}$ & $\begin{array}{r}\text { Women without } \\
\text { difficulty } \\
(\mathrm{n}=4)\end{array}$ & $\begin{array}{r}\text { Men with } \\
\text { difficulty } \\
(\mathrm{n}=7)\end{array}$ & $\begin{array}{r}\text { M en without } \\
\text { difficulty } \\
(\mathrm{n}=4)\end{array}$ \\
\hline$<6$ months & 0 & 3 & 0 & 3 \\
Short followed by long & 1 & 0 & 1 & 0 \\
Short followed by open & 3 & 1 & 0 & 0 \\
Long followed by short & 2 & 0 & 5 & 0 \\
Always long (1+ years) & 1 & 0 & 0 & 1 \\
N ever gotten pregnant & 4 & 0 & 1 & 0 \\
\hline
\end{tabular}


having another child with her husband, but when her first child was two years old, the husband left for South A frica, leaving her in doubt as to whether she had a problem getting pregnant or not.

Interviewer: D o you think you have a problem?

R espondent: I fel so.

Interviewer: W hy do you think so?

R espondent: I fed so because my child is now old and those who delivered together with me have two or three children, others have four, but I only have one.

Her previous unanswered doubts about her ability to become pregnant again, and the fact that she doesn't have the number of children that she felt she should have led her to suspect that she had a problem getting pregnant, even though she had not since been in a stable sexual relationship. Though it is difficult to discern if there is a physiological fertility problem or only the perception of a problem in this case, as in many of the interviews, it is the perceptions that matter in the lives of these individuals, influencing their attitudes, relationships and behaviours. Individuals in this setting do not wait long before trying to identify and treat a perceived fertility problem. It is specifically for this reason that individual perceptions of fertility difficulties need to be considered in order to reduce risky sexual behaviours related to perceived infertility and to reduce demand for early infertility treatment.

\section{E xplaining F ertility Problems}

D uring the period of waiting until pregnancy is achieved, women and men are watchful, looking for the first signs of pregnancy. They are usually concerned about what others, especially in-laws, are thinking or saying and curious to know why it is taking so long. Attribution of the problem to one partner or another occurs during this time.

coos tenpu A s.o h e . $10 \mathrm{~V}$ तगा
A mong the interview respondents, fertility problems were most commonly attributed to the spouse that had either not yet produced any offspring or who was unable to produce offspring with other people during this time. Eight of the eleven women confided that they knew they were the ones having the fertility problem, because their spouses had already had other children or were currently fathering a child (or children) with other wives or partners. Sometimes the recognition of a problem was concurrent with the identification of who was responsible for it, as shown by the following responses:

I discovered (a problem) when I saw that my husband had a child somewhere, but I have never become pregnant. This is when I said aah, my husband has had a child but not me, so I have a problem.

W hen I first got married I stayed for ten months without being pregnant, then I felt I had a problem of not being able to have children. M y husband had a girlfriend by then and shewas able to become pregnant, so I knew this problem is with me.

Five women also mentioned having physical problems, such as abdominal pains, irregular menstrual periods, a kinked or turned uterus, or other physical conditions that indicated that the problem "lay" with them. M en most often mentioned marrying women at "tender ages", which prevented them from becoming pregnant in the anticipated period:

For (our first) child to beborn, it took us oneand a half years because my wife was still young so that shecould not bepregnant. M mmm I discovered after six months that she had not yet matured (had not reached menarche).

Interviewer : So during those one and a half years you stayed before your wife became pregnant, what did peoplesay?

R espondent: They were saying that I am barren, but they were not saying that my wife was barren.

Interviewer: W hy were they saying that you were barren? 
Respondent: They were saying that because they did not know what was happening in my family, between me and my wife, those were just talks of people outside my family. I had a very big problem because people were telling my wife that she married a barren husband and 'as you have married the barren husband, he will not assist you' because what (everyone needs) is to have children.

Perhaps as a result of the difficulty in locating men willing to discuss their own fertility problems, only one man attributed his fertility difficulties to himself, while another shared the burden of the problem with his spouse, stating that he and his wife had had infections that could have prevented pregnancy (specifically mentioning syphilis). The rest of the men interviewed either did not know who had the problem or felt that the problem was with their spouse. The women felt that the problem was with them, even if it had been years since their partner had children with them or anyone else.

There was little mention of witchcraft, either by women or men, when discussing their personal circumstances. However, this was not the case when asked about the fertility problems of others within the community. Being bewitched emerged as a common explanation for the fertility problems of others, especially when no other explanation of infertility was easily apparent. Some people mentioned ST I s or having sex with too many partners as a cause of infertility in others, even though only one (male) respondent actually felt either of these contributed to his fertility problems. Although it was obvious that there is recognition in the community that certain patterns of sexual behaviour can lead to fertility problems, there appeared to be a lack of association of how one's own sexual history could be related to fertility problems. In addition, none of the women mentioned that her fertility problem could be due to her partner's infertility or to have resulted from infections from her partner. Instead, ownership of the problem was expressed in terms of belonging entirely to the woman, especially when the spouse had proof of current or previous fertility by having children with someone else.

\section{Discussion}

By examining how individuals perceive their fertility experiences, we gained awareness of what influences the identification of fertility problems. This type of research informs our understanding of the social construct of infertility, i.e., how fertility problems are recognised and attributed. This study considered the role that fertility expectations play in the recognition of fertility problems. It was shown that fertility demand, especially in the form of expectations about the length of time it should take a couple to produce a pregnancy, is continually compared against actual fertility experiences. Problems in getting pregnant and potential infertility are recognised when the time it "should" take to become pregnant is exceeded. Pressures from spouses, family members, friends and others in the community also inform individuals that they are experiencing a non-normative waiting time until pregnancy, and promote the use of traditional medicines, finding new sexual partners, separation or divorce, or other means of achieving a pregnancy. In this way, fertility demand plays a key role in creating the context in which fertility expectations are formed and fecundity experiences are interpreted. Even where ideal family size appears to be declining, high fertility demand, in the form of high fecundity expectations, still leads to a high rate of perceived problems in this population.

A frican men's observations and experiences regarding infertility are often lacking in research. ${ }^{25}$ Although men were included in this study, recruitmentobstacles prevented a closer examination of the forces that inform men of their fecundity and fertility problems. The unwillingness of men to participate in the study could be due to the stigma associated with infertility, as one man exclaimed: "we do not want others to think we are 
incapable of having children." H owever, the men that were interviewed provided much insight as to how they have defined and experienced the fertility problems they attribute to their wives. From the interviews, it is clear that men suffer public humiliation for not being able to prove themselves as "real" men, even when it is the wife who is considered to have the problem. With attention focused on their lack of progeny, men contribute to the pressures of fertility demand by encouraging wives to seek treatment (often taking medicines themselves), and seeking pregnancies elsewhere if treatment fails. The practice of seeking pregnancies with other individuals, often while still married, exposes the men and their partners to potentially harmful ST Is especially HIV in an area where $15 \%$ of adults are estimated to be HIV-positive.

The perception of fertility difficulties leads many individuals to seek treatment as early as a problem is suspected, most often from local traditional healers. The results of this analysis provide insight into a few ways in which education can help prevent perceived fertility problems and reduce the recognition of problems where none may yet exist. First, education for all community members about normal variation in lengths of waiting time until pregnancy would be beneficial, though it is acknowledged that such information would always be competing with the observations of other village members conceiving quickly and without problems. In this regard, field health workers and local traditional educators (such as nankungwis) could help spread the message. Although this type of education will not decrease the number of couples with clinical fertility problems, it could positively impact the number of fecund individuals seeking unnecessary treatment as well as lessen the pressure placed on individuals who are taking longer than a few months to conceive.

$M$ any respondents knew enough about the potentials of having multiple sexual partnership and ST Is for causing infertility, thus indicating a significant degree of success in education about the causes of infertility. H ow this knowledge has been interpreted at a personal level is less clear, as implied by the lack of identifying any consequence of sexual behaviour as acause of one's own problems and by the number of reports of concurrent sex partners or separations leading to new sexual partners from individuals seeking children. In a setting where HIV is very prevalent, there is a need for the community to understand that the search for pregnancies with other individuals can pose a significant health risk. In fact, the knowledge and behaviours needed for the prevention of infertility caused by exposure to ST Is mirror those needed for the prevention of HIV and, therefore, are messages that can be interwoven in existing health programmes. ${ }^{26}$ Such education should include information on how ST Is can cause infertility in women and men at any time in the reproductive years, even after the birth of a child.

\section{References}

1. D yer $S), A$ brahams $N A, H$ offman $M$ and van der Spuy ZM. "M en leave me as I cannot have children": Women's experiences with involuntary childlessness. H um R eprod 2002; 17: 1663-1668.

2. G errits T. Social and cultural aspects of infertility in M ozambique. Patient E duc Couns 1997; 31: 39- 48.

3. Pearce TO. She will not be listened to in public: Perceptions among the Yoruba of infertility and childlessness in women. $R$ eprod $H$ ealth $M$ atters 1999; 7: 69-79.

4. G ijsels M, M galla Z and Wambura L. "N o child to send": Context and consequences of female infertility in northwest Tanzania. In: Boerma JT and $M$ galla $Z(E d s$.$) . W omen and Infertility in sub-$ Saharan A frica: A M ulti-D isciplinary Perspective. The N etherlands: K IT Publishers, 2001, 203-221.

5. M gallaZ and BoermaJT. The discourse of infertility in Tanzania. In: Boerma JT and M galla Z (Eds.). W omen and Infertility in sub-Saharan A frica: A M ulti-D isciplinary Perspective. The N etherlands: K IT Publishers, 2001, 189-200. 
6. Sundby J. Infertility in the Gambia: traditional and modern health care. Patient $E$ duc C ouns 1997; 31: 29-37.

7. I kechebelu JI, I kegwuonu SC and Joe-I kechebelu N N. H IV infection and sexual behavior among infertile women in southeastern $\mathrm{N}$ igeria. J 0 bstet $G$ ynaecol 2002; 22: 306-307.

8. Favot I, N galula J, M galla Z, K lokke AH, Gumodoka B and Boerma JT. HIV infection and sexual behavior among women with infertility in Tanzania: A hospital based study. Int J E pidemiol 1997; 26: 414-419.

9. Runganga $A O$, Sundby J and Aggleton P. Culture, identity and reproductive failure in $\mathrm{Z}$ imbabwe. Sex ualities 2001; 4(3): 315-332.

10. Sundby J, M bogeR and Sonko S. Infertility in the $G$ ambia: frequency and health care seeking. Soc Sá M ed 1998; 46(7): 891-899.

11. Feldman-Savelsberg P. Plundered kitchens and empty wombs: fear of infertility in the Cameroonian grasslands. Soc Sci M ed 1994; 39: 463-474.

12. Inhorn MC. Interpreting infertility: Medical anthropological perspectives. Soc Sà M ed 1994; 39: 459-461.

13. BoermaJT and M gallaZ. Introduction. In: Boerma JT and M galla Z (Eds.). W omen and I nfertility in subSaharan A frica: A M ulti-D isciplinary Perspective. The N etherlands: K IT Publishers, 2001, 13-23.

14. Leonard L. "L ooking for Children": the search for fertility among the Sara of southern Chad. M ed A nthropol 2002; 21: 79-112.

15. E asterlin RA. A n economic framework for fertility analysis. Stud Fam Plann 1975; 6: 54-63.

16. E asterlin RA. The economics and sociology of fertility: a synthesis. In: Tilly C (E d.). H istorical Studies of $C$ hanging $\mathrm{F}$ ertility. Princeton: Princeton U niversity Press, 1978, 57-133.

17. Frank 0 . The demand for fertility control in subSaharan Africa. Stud Fam Plann 1987; 4: 181-201.
18. Westoff $\mathrm{CF}$ and A kinrinola B. Trends in the demand for family limitation in developing countries. Int Fam Plan Perspect 2000; 26(2): 56-62.

19. Jensen A. P rospect of a decline in fertility in SubSaharan A frica: a review of the recent debate. A da Sociol 1995; 38: 263- 273.

20. Larsen $\mathrm{U}$ and Raggers $\mathrm{H}$. Levels and trends in infertility in sub-Saharan A frica. In: Boerma JT and $M$ galla $Z$ (E ds.). W omen and Infertility in subSaharan A frica: A M ulti-D isaplinary Perspective. The $N$ etherlands: K IT Publishers, 2001, 25-69.

21. N ational Statistical Office (Malawi). Table 5.3 Population by religion and sex for southern region D istricts. $1998 \mathrm{M}$ alawi Population and $\mathrm{H}$ ousing Census [0n-line]. Available: http:// www.nso.malawi.net/ data on line/ demography/ census 98/ table 05.1-05. $\overline{3} . x \mathrm{~s}$

22. Center for Social Research, Save the Children Federation USA, M alawi Ministry of $H$ ealth and Population, MEASURE Evaluation. Avoiding unwanted pregnancy and sexually transmitted infections: A rural M alawi district study. Chapel H ill, N C: M E ASURE / Evaluation, 2004.

23. N ational Statistical $O$ ffice (M al awi) \& O RC M acro. $M$ alawi $D$ emographic and $H$ ealth Survey 2000. Zomba, Malawi and Calverton, M aryland: $\mathrm{N}$ ational Statistical O ffice and O RC M acro, 2001.

24. Barden-O 'Fallon J, Tsui AO and Suchindran CM. $D$ ifferences in fertility schedules according to the self-reported fecundity status of rural $M$ alawian women. Paper submitted for publication, 2004.

25. Van Balen $\mathrm{F}$ and Inhorn MC. Interpreting infertility: a view from social sciences. In: Inhorn $M C$ and Van Balen $F(E d s$.$) . Infertility around the$ $G$ lobe: $N$ ew Thinking on Childlessness, $G$ ender and $R$ eproductive T echnologies. Berkeley: U niversity of California Press, 2002, 3-32.

26. O konofua $F$. Infertility and women's reproductive health in A frica. A fr J R eprod H שalth 1999; 3(1): 7-9. 